\title{
SEARCHING SOLAR PERIODICITIES IN THE LATE GLACIAL RECORD OF ATMOSPHERIC RADIOCARBON
}

\author{
Tomasz Goslar $\bullet$ Nadine Tisnérat-Laborde ${ }^{2}$ Martine Paterne \\ ABSTRACT. Accelerator mass spectrometry radiocarbon (AMS ${ }^{14} \mathrm{C}$ ) dating of the late glacial section of laminated sedi- \\ ments from Lake Gościąż and Lake Perespilno, Poland, performed with time resolution of 20-30 years suggests quasi-perio- \\ dic oscillations of $\Delta^{14} \mathrm{C}$. The regularity of oscillations has been checked by the Maximum Entropy and Fast Fourier Transform \\ methods (MEM and FFT), which revealed peaks at 200 and $230 \mathrm{yr}$. These periods are similar to those found in the high-pre- \\ cision Holocene $\Delta^{14} \mathrm{C}$ record, and attributed to the changing sun. The analytical assessment of the significance of the FFT and \\ MEM peaks is problematic because of non-uniform spacing and various uncertainties in the input data. The significance of \\ the peaks has therefore been studied by the Monte-Carlo method. Because the original data were approximated with a spline \\ function, the amplitude of the MEM and FFT peaks depends on the stiffness of the spline, which is strongly related to the \\ "real" uncertainty of ${ }^{14} \mathrm{C}$ ages. The Monte-Carlo experiments demonstrate that the significance levels of the MEM and FFT \\ peaks also depend on the spline stiffness. Therefore, the existence of solar ${ }^{14} \mathrm{C}$ variations in the Late Glacial remains an open \\ question.
}

\section{INTRODUCTION}

Past variations of radiocarbon concentration in the atmosphere have been extensively studied for almost 30 years, to calibrate ${ }^{14} \mathrm{C}$ dates, as well as to derive the changes in intensity of cosmic rays and in the global carbon cycle. The long-term trend of ${ }^{14} \mathrm{C}$ concentration over approximately 30,000 years had been recognized as depending on geomagnetic dipole moment (Stuiver et al. 1991; Stuiver and Braziunas 1993a), which controls the intensity of cosmic rays and hence the ${ }^{14} \mathrm{C}$ production rate in the atmosphere. Shorter fluctuations of ${ }^{14} \mathrm{C}$ (of the order of several hundred years) in the Holocene have been attributed to changing magnetic field of the sun (Stuiver and Quay 1980; Beer et al. 1988; Bard et al. 1997). In fact, these fluctuations were used as proxy data for reconstruction of past changes of solar activity.

In recent years, serious efforts to extend the detailed ${ }^{14} \mathrm{C}$ calibration to the Late Glacial have been made (Bard et al. 1996, 1998; Edwards et al. 1993; Goslar et al. 1995, 1999; Hughen et al. 1998; Kitagawa and van der Plicht 1998). These efforts received added stimulus from the growing interest in reconstructing changes in the North Atlantic deep water (NADW) flux, which have been proposed as the driving force for large scale climatic changes (Broecker and Denton 1989; Broecker 1994). A few studies indicated an especially broad maximum of ${ }^{14} \mathrm{C}$ concentration in the Younger Dryas (YD) cold period that has been interpreted as the result of drastic weakening of ventilation of deep oceans (Goslar et al. 1995, 1999; Björck et al. 1996; Stocker and Wright 1996; Hughen et al. 1998). However, the role of a changing sun in the Late Glacial ${ }^{14} \mathrm{C}$ record has been neglected. One serious reason was that the time resolution of available ${ }^{14} \mathrm{C}$ reconstructions was too low to detect the ${ }^{14} \mathrm{C}$ variations of the length attributable to the sun.

Recently, a new ${ }^{14} \mathrm{C}$ record (Figure 1a) has been obtained from the studies of annually laminated sediments of Lake Gościąż and Lake Perespilno in Poland (Goslar et al. 2000a, 2000b). This record strongly suggests that the YD ${ }^{14} \mathrm{C}$ maximum was smaller than previously believed, and possibly caused by changing solar activity. The high time resolution of this record ( $20-30 \mathrm{yr})$ allows us also to search for short-term ${ }^{14} \mathrm{C}$ variations, similar to the solar-type fluctuations known for the Holocene.

\footnotetext{
${ }^{1}$ Institute of Physics, Adam Mickiewicz University, Umultowska 85, 61-614 Poznan. Present address: Institute of Physics, Adam Mickiewicz University, Umultowska 85, 61-614 Pozań, Poland. Email: goslar@ radiocarbon.pl.

${ }^{2}$ Laboratoire des Sciences du Climat et de l'Environnement, CNRS-CEA, 91198 Gif sur Yvette, France
}

(C) 2001 by the Arizona Board of Regents on behalf of the University of Arizona Radiocarbon, Vol 43, Nr 2A, 2001, p 339-344

Proceedings of the 17 th International ${ }^{14} \mathrm{C}$ Conference, edited by I Carmi and E Boaretto 


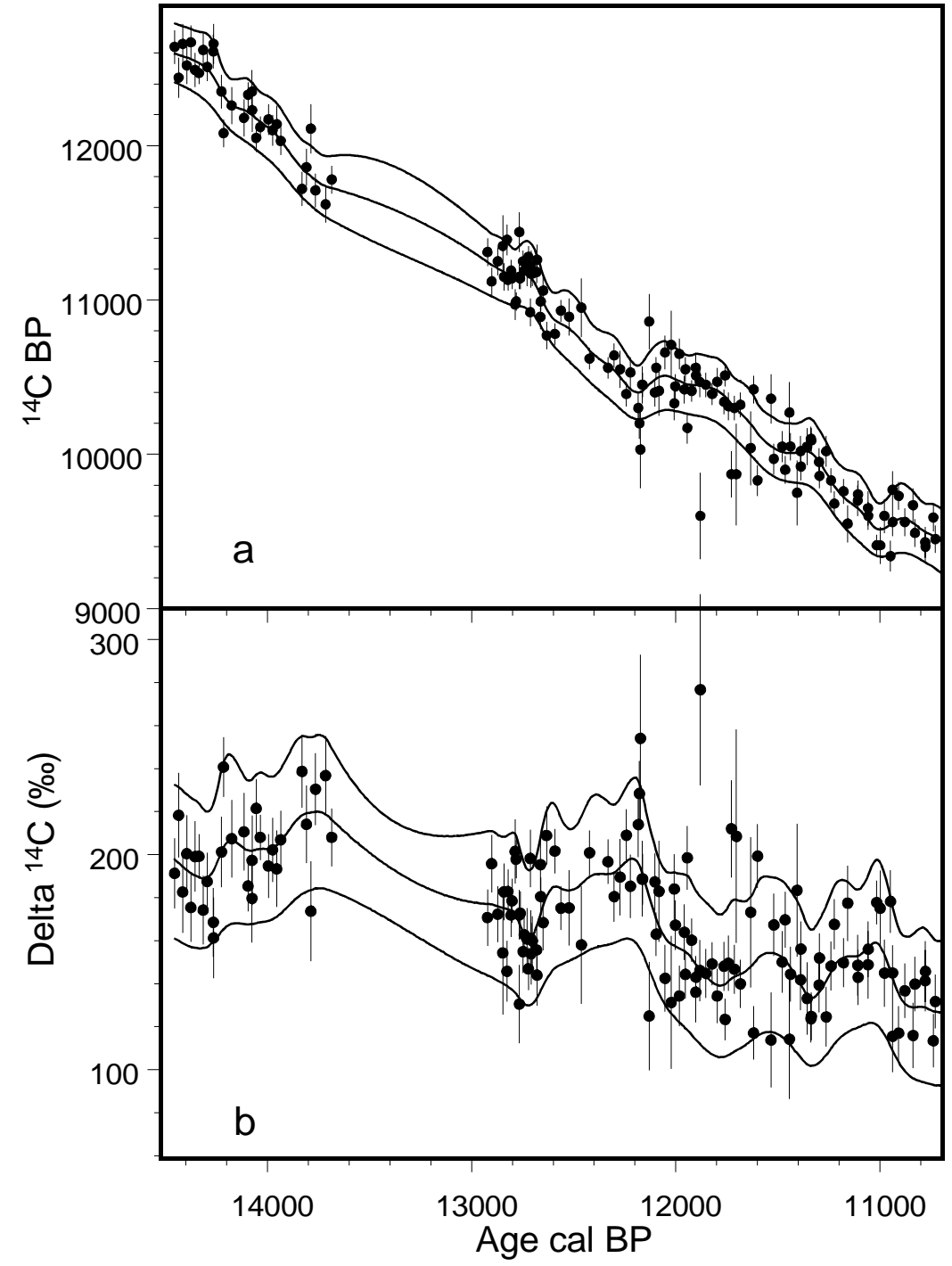

Figure 1a ${ }^{14} \mathrm{C}$ versus calendar ages of samples from Lake Gościąż and Lake Perespilno, Poland. The smooth curves represent spline functions fitted to the data for different smoothing factors. For better visibility, the lower and upper curves have been shifted from their original position. The mean-square deviations of ${ }^{14} \mathrm{C}$ ages from the fits are equal to $1.17 \times$ standard error, $1.23 \times$ standard error and $1.28 \times$ standard error for the upper, middle and lower curve, respectively. $b:{ }^{14} \mathrm{C}$ concentrations in the atmosphere, derived from the data shown in Figure 1a. The smooth curves have the same meaning as in Figure $1 a$. 


\section{THE SPECTRUM OF ATMOSPHERIC $\Delta^{14} \mathrm{C}$ RECORD}

The record of $\Delta^{14} \mathrm{C}$, derived from the ${ }^{14} \mathrm{C}$-calendar age data from Gościąż and Perespilno (Figure $1 b$ ), suggests the occurrence of quasi-periodic oscillations of the length of around 200 years. The regularity of oscillations between 14,455 cal BP and 10,870 cal BP (134 samples) has been checked by the Fast Fourier Transformation and Maximum Entropy methods (Press et al. 1989). Both methods reveal periodicity of about 229 years. A weaker periodicity at $195 \mathrm{yr}$, is also distinctly visible in the MEM spectrum (Figure 2). These periods are surprisingly similar to those found (Stuiver and Braziunas 1993a) in the high-precision $\Delta^{14} \mathrm{C}$ data from later periods (207 yr, $226 \mathrm{yr}$ and around 217 yr for 4-0 ka BP, 8-4 ka BP and 11.4-8 ka BP, respectively), and attributed to the changing sun (Stuiver et al. 1991).

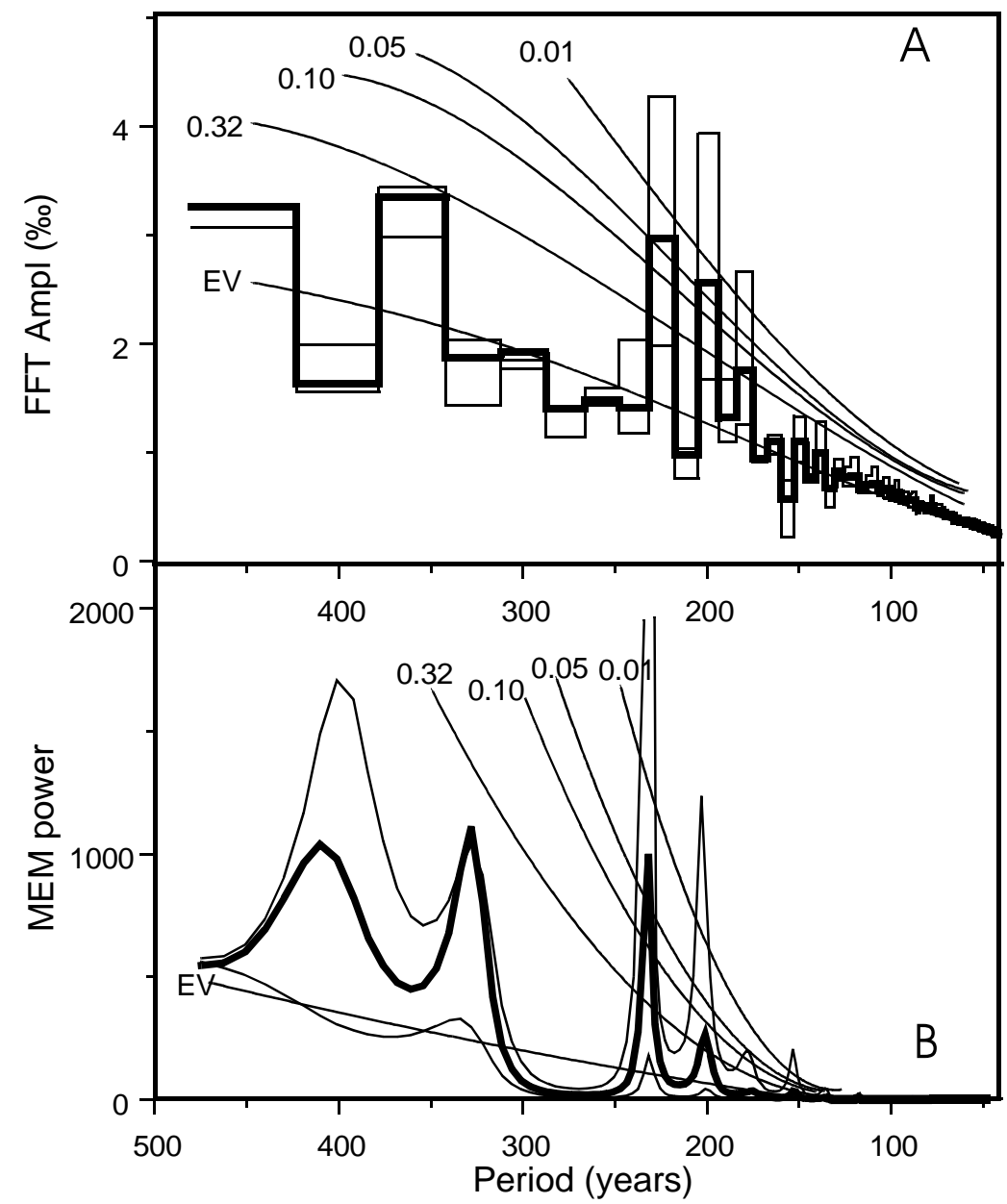

Figure 2 FFT (part A) and MEM (part B) spectra of the spline functions fitted to the calibration data from Lake Gościąż and Perespilno. The spectra obtained for error multiplier $\mathrm{M}=1.23$, are shown by thick lines. The lines above and below display spectra for $\mathrm{M}=1.17$ and $\mathrm{M}=1.28$, respectively. Thin lines indicate expected values of the MEM power and FFT amplitude, and critical values at the levels of significance of 0.01, 0.05, 0.10 and 0.32 , calculated using the Monte-Carlo experiments. 
Analytical assessment of significance of the FFT and MEM peaks is problematic because of various errors in the input data and its non-uniform spacing. For that reason, in the FFT and MEM procedures, we had to use $\Delta^{14} \mathrm{C}$ values obtained by smoothing the original ${ }^{14} \mathrm{C}$ record with the spline function, which is intended to represent the "true" calibration curve. As the original data were approximated with the spline function, the amplitudes of the MEM and FFT peaks depend on the smoothing parameter (stiffness) of the spline (Figure 2).

The choice of the spline stiffness is related to our confidence in the raw data. In general, the smoother the spline the larger the mean-square deviation of the original data from the spline (Figure 1). At a first approximation, one should assume that deviation equal to standard error of single measurements. Allowing for smoother spline we agree that real uncertainties of our data are $\mathrm{M}(\mathrm{M}=$ multiplier) times larger than laboratory errors. For all the fitted splines (Figure 1a), the mean-square deviation of ${ }^{14} \mathrm{C}$ date is bigger than the standard error. This is not surprising, as the imprecision of ${ }^{14} \mathrm{C}$ dating is superimposed on an uncertainty of calendar age. The latter is caused by the non-zero thickness of the sample and by possible problems with redeposition and post-depositional transport of macrofossils. Comparison of the Gościąż-Perespilno ${ }^{14} \mathrm{C}$ dates with the tree-ring calibration curve between 11.65 and $10.3 \mathrm{ka} \mathrm{BP}$ suggests that the real error is about 1.23 times the standard precision of ${ }^{14} \mathrm{C}$ measurement (Goslar et al. 2000b).

On the other hand, smoothing parameter is critical for height of peaks obtained with the MEM and FFT methods. Of course, the smoother is the spline (Figure 1), the lower are peaks of the MEM and FFT spectra (Figure 2).

\section{THE MONTE-CARLO APPROACH}

The significance of the MEM and FFT peaks has been studied with the Monte-Carlo method. In this method, artificial sets of data points were generated many times and the splines and MEM and FFT spectra were calculated in the same way as for the real data. The calendar ages of artificial points were kept as in the original data set, while ${ }^{14} \mathrm{C}$ ages were generated randomly, according to gaussian distributions. The expected values of these distributions were derived from the long-term trend of $\Delta^{14} \mathrm{C}$ (Goslar et al. 2000a), and the dispersions were set $\mathrm{M}$ times the standard error of real ${ }^{14} \mathrm{C}$ date. As a measure of significance level, the number of trials giving the MEM power (or FFT amplitude) higher than a critical value was used.

Both the MEM (and FFT) spectra are discrete, and in the interval 100-500 years, they give powers for 145 (MEM) and 29 (FFT) different periods. Of course, in a Monte-Carlo trial, probability of random occurrence of high power (i.e. that exceeding the critical value) for any period, is higher than probability of high power for the particular period. With no a priori knowledge, the significance level of any peak should thus be proportional to the total number of randomly obtained high powers, in the whole interval of considered periods. In our case, periodicity of solar origin was expected somewhere between 240 and 200 years, so, in determination of significance level, the number of high powers from just that range was used.

\section{SIGNIFICANCE LEVEL OF THE 'SOLAR' PEAKS OF $\Delta^{14} \mathrm{C}$}

The Monte-Carlo experiments suggest that, with $\mathrm{M}=1.23$ both the MEM and FFT maxima at around 230 years are significant at the level of $5 \%$ (Figure 2).

Obviously, the heights of the MEM (FFT) maxima depend on the spline stiffness. Also the significance levels should depend on that parameter. In general, the greater error multiplier is assumed, the 
smoother is the spline and in the Monte-Carlo trials lower spectral amplitudes should be obtained. This has been confirmed by the Monte-Carlo experiments, carried out for several smoothing factors, corresponding to different values of the error multiplier $\mathrm{M}$. The results show fast decrease of the critical values of the 230-yr peaks for both the MEM and FFT spectra (see Figure 3). However, this decrease is not as fast as for the peaks obtained with the real data. One can see that the MEM peaks become insignificant at the level of 0.1, when the error multiplier exceeds 1.29. This loss of significance is even more distinct in the FFT method.

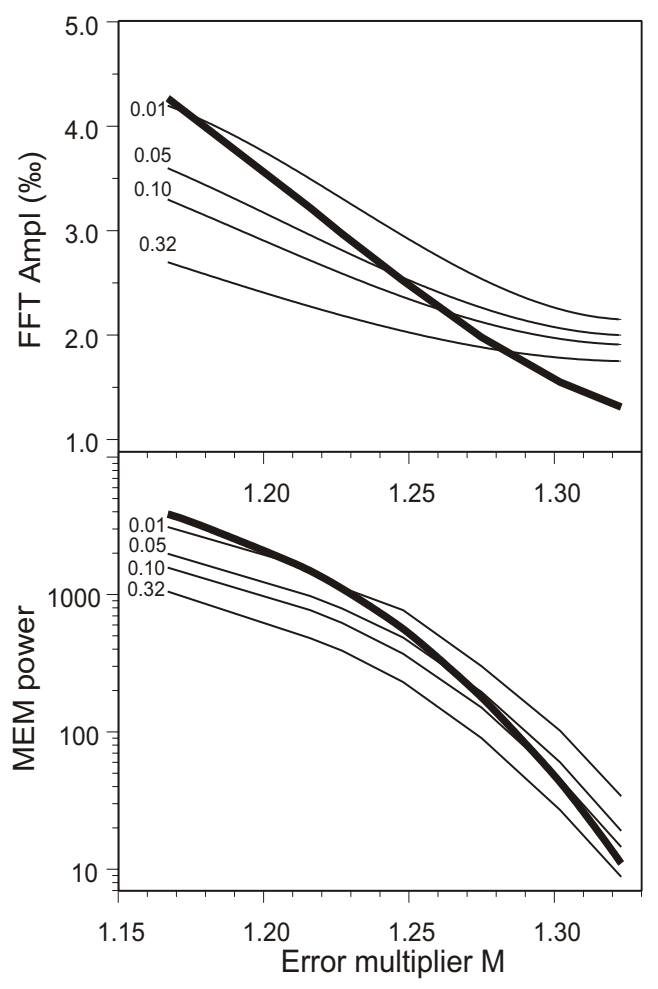

Figure 3 FFT amplitude (upper part) and MEM power (lower part) of the 230 -yr peak of the spectra obtained for the Gościąż and Perespilno ${ }^{14} \mathrm{C}$ dates vs. error multiplier of ${ }^{14} \mathrm{C}$ ages. Dashed lines illustrate the dependence of critical values on the error multiplier $\mathrm{M}$, calculated using the Monte-Carlo experiments

The dependence of significance level on the error of data is not surprising, as we bear with the quite weak effect. In the Holocene, the peak-trough amplitude of 200-240 years periodical component in the Holocene record is only $\pm 3-6 \%$ (Stuiver and Braziunas 1993b). This corresponds to the error of ${ }^{14} \mathrm{C}$ age of $\Delta \mathrm{T}=16-50 \mathrm{yr}$, which is significantly less than the error of single ${ }^{14} \mathrm{C}$ date from Gościąż and Perespilno. Therefore, to detect the periodicity many data per period is required. The ultimate detectable amplitude can be estimated by the formula:

$$
A=\frac{\Delta T}{\sqrt{n}},
$$

which for $\mathrm{n}=10$ (number of data points per period) and $\Delta \mathrm{T}=130 \mathrm{yr}$ gives approximately 40 years, comparable with the amplitude of solar periodicity in the Holocene. Therefore, distinct increase of error multiplier beyond the value of $\mathrm{M}=1.23$, with no change in time resolution of the reconstruction, can make the detection of so weak periodicity impossible. 
The problem is that the value of the error multiplier can be only assumed. Comparison of the Gościąż-Perespilno ${ }^{14} \mathrm{C}$ dates with the tree-ring calibration curve between 11.65 and $10.3 \mathrm{ka} \mathrm{BP}$ suggests value $\mathrm{M}=1.23$, but the error of ${ }^{14} \mathrm{C}$ dates in the Younger Dryas period may be larger than in the Holocene (because of larger probability of redeposition). The correctness of our estimate of $\mathrm{M}$ (=1.23) seems to be supported by the amplitude of the $230-200$ years component $( \pm 2-6 \%$ o when both the 230-yr and 200-yr periodicities are superimposed) which is in agreement with that found in the Holocene. Nevertheless it is possible that $\mathrm{M}$ is larger, the periodic signal non-detectable and that the amplitudes produced by the FFT algorithm do not reflect real periodicity. Therefore, the existence of solar ${ }^{14} \mathrm{C}$ variations in the late glacial, remains an open question.

\section{ACKNOWLEDGMENTS}

This study has been financially supported by the Polish Committee for Scientific Research through the grant nr 6 P04E 04616.

\section{REFERENCES}

Bard E. 1998. Geochemical and geophysical implications of the radiocarbon calibration. Geochimica et Cosmochimica Acta 62:2025-38.

Bard E, Hamelin B, Arnold M, Montaggioni L, Cabioch G, Faure G, Rougiere F. 1996. Deglacial sea-level record from Tahiti corals and the timing of global meltwater discharge. Nature 382:241-4.

Bard E, Raisbeck GM, Yiou F, Jouzel J. 1997. Solar modulation of cosmogenic nuclide production over the last millennium: comparison between ${ }^{14} \mathrm{C}$ and ${ }^{10} \mathrm{Be}$ records. Earth and Planetary Science Letters 150: 453-62.

Beer J, Siegenthaler U, Bonani G, Finkel RC, Oeschger H, Suter M, Wölfli W. 1988. Information on past solar activity and geomagnetism from ${ }^{10} \mathrm{Be}$ in the Camp Century ice core. Nature 331:675-9.

Björck S, Kromer B, Johnsen S, Bennike O. 1996. Synchronized terrestrial-atmospheric deglacial records around the North Atlantic. Science 274:1155-60.

Broecker WS, Denton GH. 1989. The role of ocean-atmosphere reorganizations in glacial cycles. Geochimica et Cosmochimica Acta 53:2465-501.

Broecker WS. 1994. Massive iceberg discharges as triggers for global climate change. Nature 372:421-4.

Edwards RL, Warren Beck J, Burr GS, Donahue DJ, Chappell JMA, Bloom AL, Druffel ERM, Taylor FW. 1993. A large drop in atmospheric ${ }^{14} \mathrm{C} /{ }^{12} \mathrm{C}$ and reduced melting in the Younger Dryas, documented with ${ }^{230} \mathrm{Th}$ ages of corals. Science 260:962-8.

Goslar T, Arnold M, Bard E, Kuc T, Pazdur MF, RalskaJasiewiczowa M, Tisnerat N, Różański K, Walanus A, Wicik B, Więckowski K. 1995. High concentration of atmospheric ${ }^{14} \mathrm{C}$ during the Younger Dryas cold episode. Nature 377:414-7.

Goslar T, Wohlfarth B, Björck S, Possnert G, Björck J. 1999. Variations of atmospheric ${ }^{14} \mathrm{C}$ concentrations over the Alleröd-Younger Dryas transition. Climate
Dynamics 15:29-42.

Goslar T, Arnold M, Tisnerat-Laborde N, Czernik J, Więckowski K. 2000a. Variations of Younger Dryas atmospheric radiocarbon explicable without ocean circulation changes. Nature 403:877-80.

Goslar T, Arnold M, Tisnerat-Laborde N, Hatté Ch, Paterne M, Ralska-Jasiewiczowa M. 2000b. Radiocarbon calibration by means of varve versus ${ }^{14} \mathrm{C}$ ages of terrestrial macrofossils from Lake Gościąż and Lake Perespilno, Poland. Radiocarbon 42(3):335-48.

Hughen KA, Overpeck JT, Lehman SJ, Kashgarian M, Southon J, Peterson LC, Alley R, Sigman D. 1998. Deglacial changes in ocean circulation from an extended radiocarbon calibration. Nature 391:65-8.

Kitagawa H, van der Plicht J. 1998. Atmospheric radiocarbon calibration to 45,000 yr B.P.:Late Glacial fluctuations and cosmogenic isotope production. Science 279:1187-90.

Press WH, Flannery BP, Teukolsky WT, Vetterling WT. 1989. Numerical recipes in Pascal. Cambridge University Press.

Stocker TF, Wright DG. 1996. Rapid changes in ocean circulation and atmospheric radiocarbon. Paleoceanography 11:773-95.

Stuiver M, Quay PD. 1980. Changes in atmospheric carbon-14 attributed to a variable Sun. Science 207:11-9.

Stuiver M, Braziunas T, Becker B, Kromer B. 1991. Climatic, solar, oceanic, and geomagnetic influences on Late-Glacial and Holocene atmospheric ${ }^{14} \mathrm{C} /{ }^{12} \mathrm{C}$ change. Quaternary Research 35:1-24.

Stuiver M, Braziunas T. 1993a. Modeling atmospheric ${ }^{14} \mathrm{C}$ influences and ${ }^{14} \mathrm{C}$ ages of marine samples to 10,000 BC. Radiocarbon 35(1):137-89.

Stuiver M, Braziunas T. 1993b. Sun, ocean, climate and atmospheric ${ }^{14} \mathrm{CO}_{2}$ : an evaluation of causal and spectral relationships. The Holocene 3:289-305. 